\title{
Organização: critérios para uma concepção crítica e objetiva
}

\section{Organization: criteria for a critical and objective conception}

Paulo Tromboni Nascimento ${ }^{1}$

\begin{abstract}
Resumo
O conceito de organização é, muitas vezes, utilizado de modo subjetivo, vago e até equivocado. Aqui se buscam critérios para criticar e julgar de modo objetivo as definições propostas ou implícitas numa pesquisa em administração. O caminho escolhido foi partir da concepção de Barnard (1942) e dialogar com a literatura científica na área. Sem cair no irracionalismo, critica-se a conceituação formalista e racionalista. Em substituição, entra a correspondência entre resultados e as cobranças das partes interessadas. Afasta-se o foco dos significados, em favor da idéia de sistema social aberto, com divisão de trabalho, reais relações de cooperação e poder e reprodução, apoiada nos resultados dos intercâmbios com o meio social onde se insere a organização. A conclusão está na forma de critérios aplicáveis a uma concepção de organização que se proponha objetiva e crítica.
\end{abstract}

Palavras-chave: definição de organização; teoria da organização; sistemas cooperativos; organização e resultados; organização e racionalidade; organização e efetividade.

\begin{abstract}
The concept of organization is often used in subjective, vague and even wrong ways. In this paper, the aim is to find criteria to objectively criticize and judge definitions applied in management research. The adopted approach is to depart from Barnard's conception (1942) and to establish a dialogue with the scientific management literature. Rationalistic and formalistic conceptions are criticized. These ideas are replaced by correspondence between results and stakeholders demands. The focus on meaning is abandoned, in favor of an open social systems idea with work division, actual cooperation and power relations, and reproduction sustained by exchange with the organization social environment. In conclusion, a set of criteria is formulated to evaluate the objective and critical character of any proposed formal definition of organization.
\end{abstract}

Keywords: organization definition; theory of organization; cooperative systems; results and organization; rationality and organization; organization and effectiveness.

\footnotetext{
Doutor em Administração pela Faculdade de Economia, Administração e Contabilidade da Universidade de São Paulo . Professor da Faculdade de Economia, Administração e Contabilidade da Universidade de São Paulo - FEA/USP - Endereço: Av. Prof. Dr. Luciano Gualberto, 908 , sl. E 111 - Cidade Universitária - São Paulo - SP - Brasil - CEP 05508-900 - E-mail: tromboni@usp.br

Artigo submetido em novembro e aceito em dezembro de 2008
} 


\section{Introdução}

March e Simon (1958, p.4) realçam a importância das organizações no mundo moderno.

Organizações são grupos de seres humanos em interação e são os maiores grupos em nossa sociedade que tem qualquer coisa que pareça um sistema central de coordenação ... a alta especificidade da estrutura e coordenação das organizações, quando contrastada com as difusas e variáveis relações entre as organizações e indivíduos desorganizados, realça a organização como uma unidade sociológica comparável em significado ao organismo individual na biologia (tradução do autor). ${ }^{1}$

Quando se faz pesquisa em administração, a palavra organização é utilizada explicita ou implicitamente. Afinal, administração é uma atividade que só ganha sentido num contexto organizacional. Mesmo assim, a palavra é quase sempre utilizada informalmente; de modo implícito e bastante vago e, até, de modo equivocado.

Para March e Simon (1958, p.1)

"É mais fácil, e provavelmente mais útil, oferecer exemplos de organizações formais do que definí-las ... não há necessidade de conhecer o desenho preciso das fronteiras em torno das organizações nem a distinção exata entre o que é e o que não é uma "organização" (tradução do autor). ${ }^{2}$

Por motivos práticos, o termo organização também é utilizado em duplo sentido. Ao mesmo tempo, é utilizado tanto para os fenômenos estudados quanto para a sua definição formal, acarretando uma ambigüidade que, quase sempre, é deixada ao esclarecimento do contexto. Tal ambigüidade é inevitável, a não ser que se aceite uma terminologia prolixa e desajeitada ${ }^{3}$, como fez Barnard (1942), quando recorreu à expressão "sistema de atividades ou forças coordenadas de duas ou mais pessoas" (tradução do autor).

Em parte, a ambigüidade é necessária. Um conceito sempre é uma abstração. Do contrário, designaria um só ente do mundo real. Seria um nome próprio. É claro que um conceito deve ser aplicável a um conjunto de entes ou fenômenos, o que é praticamente uma definição de ambigüidade. Além disso, a relação entre um conceito e a realidade a qual se refere muda, na medida em que se explora essa realidade e, também, porque os próprios fenômenos abrangidos na abstração conceitual tendem a ser recortados e ampliados com o aprofundamento da pesquisa e a evolução da prática das próprias organizações. Por outro lado, excesso de imprecisão leva à confusão de objetos que deveriam ser tratados em separado, em favor da clareza e rigor. ${ }^{4}$

Tudo isso impõe ao pesquisador e ao filósofo da administração a necessidade de adotar uma concepção explícita, objetiva e clara de organização que também não se confunda com a vaga referência às organizações reais. Este artigo tem por objetivo discutir a noção de organização. Tal objetivo, facilmente se percebe, coloca desafios ontológicos e epistemológicos, transformando este num texto de filosofia da ciência, aqui entendida como reflexão sistemática sobre questões que a ciência não sabe ou não pode responder por si mesma (ROSEMBERG, 2005, cap.1). No caso, premissas últimas e conceitos basilares, como o de organização. Na visão adotada aqui, a filosofia da ciência é uma especulação racional (RUSSEL, 1945, p.xiii) sobre problemas filosóficos com origem na ciência contemporânea (POPPER, 2002, cap.2). A especulação racional complementaria o trabalho da ciência naqueles temas e questões para os quais inexistem respostas científicas. Contudo, espera-se do filosofar que formule suas posições com base nos avanços científicos; seja para incorporá-los, seja para criticá-los. Considerando o enorme esforço realizado no século XX para entender as organizações, não há como ignorar o progresso científico na área. Daí a opção por partir da boa definição de Barnard (1942) e dialogar com a literatura científica.

Convém esclarecer que não se pretende ditar o significado da palavra organização, mas apenas refletir sobre o conceito e seus usos, apontando os componentes em que se pode decompor essa noção e como se pode rearticulá-los num todo. O que se pretende é sugerir que cada um deixe claro como formaliza esse conceito fundamental e auxiliar quem deseje criticar o seu uso pouco rigoroso e subjetivo. Cabe alertar, portanto, que este estudo se contrapõe àqueles que não vêem realidade nas organizações e pensam que são meras ficções úteis para entender um campo intersubjetivo. Um propósito aqui é frisar a realidade objetiva das organizações. 
São bem conhecidas as polêmicas que cercam termos como "objetivo" e "objetividade". Não serão tratadas aqui. Para os fins deste artigo, objetividade tem a ver com a resistência que as ações do sujeito enfrentam, impedindo que se alcance os resultados desejados. Sempre que se age, buscam-se resultados. Se eles não vêm, as ações precisam mudar, e com elas são julgados e corrigidos os modelos da situação que as embasaram. Se chove, não basta descrer vigorosamente para evitar se molhar! Para o agente, o que é vital não é a racionalidade subjetiva da ação, mas seus resultados. O assunto foi mais extensamente tratado em Nascimento (2007).

Além desta introdução, o resto do texto tem as seguintes seções:

- Por que organização formal?

- Por que organização racional?

- A atividade coletiva organizada

- A coordenação da ação coletiva

- Objetivos e resultados organizacionais

- Resultados e reprodução da organização

- Campos ou domínios da ação coletiva organizada

- A autoridade real da hierarquia e a decisão de participar

- Poder e resultados na ação organizada

- Uma tentativa de concepção crítica e objetiva

\section{Por que organização formal?}

Em Taylor não há uma teoria da organização. Implicitamente, dado o seu foco nas tarefas de produção, há uma concepção técnica da organização produtiva. Mais que isso, como lembra Thompson (1967, p.5), sua principal preocupação era com o aumento do desempenho, na forma de eficiência produtiva.

Com Taylor, as pessoas são formalmente separadas das operações produtivas que executam. Taylor explicita uma importante abstração. As operações produtivas se tornam abstrações impessoais a serem examinadas tecnicamente à luz das limitações e potencialidades genéricas dos operadores, que podem mais tarde ser recrutados e treinados de forma adequada. Assim se formaliza os processos de trabalho. Com isso, as pessoas que participam podem mudar, sem alterar a identidade da organização, que passa a ser dada pelo padrão de relações e processos sociais. ${ }^{5}$ A organização se torna um sistema de ação coletiva! Independente dos indivíduos que a compõem.

Em Fayol (1970) também não há propriamente uma teoria explícita da organização. Existe sim uma compilação empírica de regras para a boa administração da empresa. A organização que o interessa é uma com finalidades econômicas. Implicitamente, é possível discernir elementos de uma teoria da organização. Assim, toda a empresa teria operações (1970, p.1); ou seja, a realização de atividades com finalidade econômica caracterizaria a organização empresarial. Tais atividades são classificadas em técnicas, comerciais, financeiras, contábeis, de segurança e administrativas.

Segundo Fayol (1970, p.79), a empresa tem sempre uma organização material e outra social. Também deixa implícita a idéia de objetivos da organização quando afirma (1970, p.90) que dirigir é "conduzir a empresa ao seu objetivo, procurando obter o maior proveito possível dos recursos de que ela dispõe". Reconhece ainda o caráter institucionalizado da organização ao referir-se ao conselho de administração, que para ele (1970, p.89) "possui poderes estatutários muito amplos [que] delega em grande parte à direção-geral por ele nomeada". A idéia de poderes estatutários, claramente, insere a empresa no sistema legal mais amplo e formaliza sua existência e operação; além do que, claro, Fayol (1970) reconhece a existência de um conjunto de membros do corpo social da empresa que concentram as atividades e funções administrativas. Por fim, o autor (1970, p.80) compara o "serviço administrativo" ao sistema nervoso dos animais, afirmando que há "grandes analogias" entre eles. 
Desde o começo do estudo científico da administração, portanto, os aspectos formais da organização se viram realçados. Esse aspecto formal e desencarnado da organização foi especialmente realçado por Weber, ao propor o seu tipo ideal de burocracia.

Weber frisou a importância das regras de ação para disciplinar a ação coletiva organizada. Tais regras categorizam temas de ação, situações e as respostas adequadas, definindo quem pode deliberar sobre quais assuntos; como as ações devem ser implementadas, quais restrições devem ser respeitadas etc. Um resultado importante da abstração weberiana é realçar como se pode abstrair pessoas concretas das organizações, que passam assim a ser caracterizadas por um conjunto de relações sociais abstratas, portanto, formais, entre funcionários desempenhando papéis. Os funcionários aqui não são pessoas, mas agentes que se comportam conforme regras adequadas ao desempenho de seus cargos.

É possível reduzir a noção de organização a essa estrutura formal? Na verdade, toda a produção da chamada escola de recursos humanos da administração, após os experimentos de Hawthorne, serviu para demonstrar que existe uma organização informal que subsiste no interior da organização formal. Gouldner (1961) chama de abordagem de sistemas naturais essa forma de análise organizacional.

Contudo, como frisa Gouldner (1961, p.410) há o risco dessa abordagem se concentrar numa visão antiorganizacional ou disfuncional. Assim se releva a importância de fenômenos racionais na gestão das organizações, como a confecção de planos e a aferição de resultados ou o recrutamento, seleção e treinamento de pessoal em bases sistemáticas. Da mesma forma, aferrada à crítica pura e simples da organização moderna, a abordagem tende a esquecer de examinar importantes padrões latentes também informais. Ele cita exemplos deliciosos como a claque de seguidores do vendedor bem-sucedido ou o ajuntamento de homens atenciosos em torno da secretária do chefe (GOULDNER, 1961, p.411). No entanto, é claro que também pensa em padrões latentes muito mais vitais, tais como, por exemplo, as redes de relações informais entre homens poderosos nas organizações ou, ainda, em conflitos de interesses informais.

O que Gouldner (1961) deixa claro é a insuficiência da análise organizacional que desconhece padrões latentes ou informais. E também deixa claro que não se pode simplesmente contrapor o lado formal ao informal, pois tais padrões estão intimamente imbricados na constituição e operação da organização.

Embora a formalização facilite a organização em larga escala - a qual se pode, talvez, supor impossível sem ela -, a conclusão inevitável é que o fenômeno que a palavra organização modela abstratamente não pode ser reduzido a sua dimensão formal.

\section{Por que organização racional?}

Foi também Weber quem decompôs as relações sociais implicadas na divisão social do trabalho em coleções de ações sociais voltadas aos outros. Ao fazê-lo, precisou distinguir os componentes abstratos das ações sociais através de seus tipos ideais. Essas abstrações decompõem a ação social em ação racional em relação a finalidades e a valores, ações afetivas e ações tradicionais. Uma ação social qualquer é na visão de Weber uma composição desses quatro tipos ideais. É claro que a componente racional pode predominar, caso em que se fala de ação racional, o que tornaria, para Weber essa ação passível de exame objetivo, por terceiros, já que a racionalidade suposta exigiria adequação entre meios e fins. No que se refere às organizações, a burocracia ou a organização baseada em regras e rotinas formais - seria seu tipo ideal de organização voltada à eficiência, ou economia de meios na consecução dos fins, o que caracterizaria a racionalidade da burocracia e das ações dos seus agentes.

Infelizmente, caracterizar essa racionalidade instrumental exige estabelecer os objetivos do agente, algo que está em sua mente - além de sua compreensão do universo que o cerca -, o que determina sua visão dos meios necessários, ambos, na cabeça do sujeito. Além disso, nessa concepção, a racionalidade, mesmo na versão objetiva, parece depender do estado atual dos conhecimentos sobre os meios necessários a cada propósito.

Como bem lembrou Bertero (1992), a noção de racionalidade tem um núcleo central antigo na idéia de consistência do argumento, de lógica. Para tornar o assunto ainda mais complexo, parece claro que a própria 
noção de racionalidade baseada na lógica tem uma evolução histórica (DA COSTA, 1994, p.231-237). Não é suficiente conhecer os princípios básicos da lógica aristotélica para saber o que é pensamento racional. São possíveis outras lógicas. Por exemplo: a de Brower - que não aceita o princípio do terceiro excluído -, a quântica - na qual se questiona o princípio da identidade -, as lógicas de múltiplos valores de verdade ou, até, as lógicas paraconsistentes, que relaxam o princípio da não-contradição.

Por outro ângulo, a existência de vários atores influentes, individual ou coletivamente, põe em cheque quais efetivamente são os objetivos da organização. Isto é, a política e o poder de determinar os objetivos de fato perseguidos permitem comportamentos organizacionais divergentes na mesma situação e até erráticos, quando as disputas entre grupos equilibrados demoram a se resolver (MINTZBERG, 1983, cap. 2).

Via essas brechas que indicam uma componente subjetiva para a racionalidade na ação social, criou-se uma possibilidade de crítica destrutiva de uma visão objetiva da organização. Esta acabaria se dissolvendo numa teia de significados subjetivos. É argumentação baseada em exagero, já que as conexões meio fim relevantes para entender a burocracia são imediatas e operacionais.

O ponto central para este estudo, ao contrário, está em perceber que não é a racionalidade que importa para entender as organizações e para as relações entre elas e com os indivíduos, mas sim a correspondência entre expectativas (ou objetivos) dos atores, de um lado, e os resultados, de outro.

Claramente, expectativas são parte da subjetividade dos membros e interlocutores da organização. Têm ainda uma componente intersubjetiva nas expectativas explícitas e comuns daqueles que vigiam e controlam a organização ou com elas interagem. O que, necessariamente, cria alguns objetivos intersubjetivamente partilhados, além daqueles apenas individuais e, com isso, já ganham objetividade no mundo dos significados socialmente partilhados.

Quanto aos resultados, estes são essencialmente objetivos. A sua valoração pode variar com o observador, mas a sua existência é apurável no mundo real. Podem ser observados por qualquer um e aproveitados por aqueles que deles se apoderam. Resultado é o que se espera e cobra da organização. Mais que isso, a ação se ordena técnica, espacial e temporalmente, espontânea ou conscientemente, em torno de resultados. Se há desperdício, ações desnecessárias, excesso de colaboradores, nada disso impede que a organização exista. O fundamental é a eficácia. Quando se trata da constituição da organização, a eficiência só aparece depois, se e quando aparece, pela experiência e melhora do desempenho.

A noção de eficiência racional é relevante para a administração, mas não para o conceito de organização. Aliás, nada garante que uma organização aja de modo racional, mesmo quando tem clareza dos objetivos, meios necessários e disponíveis e conhecimento sobre as suas relações causais. Pode muito bem errar, ou agir a partir do interesse de atores influentes, ainda que de modo irracional para a organização como um todo. De modo mais direto, nada garante que a divisão do trabalho ou a estrutura de coordenação seja racional. Para uma organização existir, basta que as ações organizadas alcancem os resultados necessários à sua continuidade como ação coletiva coordenada. A começar, é evidente, da contribuição necessária de pessoas. Nada mais. Assim, a idéia de racionalidade só deve ser aplicada à noção de organização de modo restrito; certamente, não deve constar do âmago da compreensão do que seja uma organização.

Embora para discutir a administração das organizações em direção á eficácia e eficiência e, em particular, a atividade administrativa de divisão do trabalho e de constituição da hierarquia, seja necessário formular, julgar e discutir racionalmente as alternativas (RUTGERS, 1999), isso não significa que a própria noção de organização deva incluir a de racionalidade. Diga-se de passagem, é comum as organizações reais se distanciarem dos padrões mínimos de racionalidade de qualquer dos atores em presença. Interesses conflitantes, corrupção e compromissos entre grupos poderosos, com freqüência, levam as organizações a soluções pouco racionais. 


\section{A atividade coletiva organizada}

Embora atraente, a idéia de examinar a organização formal e enfatizar a sua racionalidade, na verdade, embute como presunção o que deveria ser, se possível, demonstrado. Adota a prescrição como parte da definição! Formalização e racionalidade são qualificações da noção de organização; não, parte intrínseca dela.

Para entender o quanto de formal e de racional tem a noção de organização, e para reconstruí-la numa perspectiva crítica e objetiva, é preciso voltar ao começo e examinar a atividade coletiva organizada!

Nos dicionários, ${ }^{6}$ no que interessa à administração, a idéia de organização está associada a um grupo de pessoas realizando um trabalho juntas, de modo ordenado, arranjado, estruturado, em função de resultados a serem alcançados. Assim, é preciso distinguir a ação individual da coletiva.

$\mathrm{Na}$ ação individual, uma só pessoa pratica os atos, embora, profundamente influenciada pelos valores, conhecimento e pressões sociais. A ação coletiva é aquela que o indivíduo não realiza sozinho. Nos casos relevantes, o indivíduo nem tem alternativa à cooperação. $\mathrm{O}$ trabalho junto com outros é inevitável, e o agir em conjunto acarreta duas consequiências importantes: a divisão e a necessidade de coordenação do trabalho.

Lembra Gullick (1937, p.3) que o trabalho se divide

"Porque os homens diferem em natureza, capacidade e habilidade, e aumentam muito sua destreza pela especialização; porque o mesmo homem não pode estar em dois lugares ao mesmo tempo; porque o mesmo homem não pode fazer duas coisas ao mesmo tempo; porque a variedade de conhecimentos $e$ habilidades é tão grande que um homem não consegue em toda sua vida saber mais do que uma pequena fração disso tudo." (tradução do autor $)^{7}$

A necessidade de cooperação se aprofunda quando o trabalho exige habilidades especiais. Atirar com arco e flechas é uma arte que alguns levam quase à perfeição. Porém, pouco tem a ver com a confecção de arcos e flechas. Por sorte, o arqueiro não precisa fabricá-los para usá-los. Basta um armeiro tê-los feito antes. A divisão do trabalho em função das habilidades requeridas, exercitadas e aperfeiçoadas é uma necessidade quando os recursos são limitados. Torna-se ainda mais vital quando há concorrência.

Acima, há a divisão seqüencial do trabalho. No entanto, há ainda a divisão de trabalho simultânea ou quase. Uma equipe de futebol precisa de goleiros, de meios-campo, dos atacantes e da defesa. Esta, por sua vez, precisa de zagueiros e de laterais. Cada esforço individual só contribui para resultados práticos no contexto de uma divisão de trabalho, na qual um conjunto de ações produz algo útil - no exemplo clássico de Smith (1979), apenas cortar o fio não é útil isoladamente, mas só no contexto da fabricação de alfinetes -; ou ainda quando há divisão intelectual do trabalho, como na feitura do desenho de uma peça como premissa para o trabalho do operário.

Nasce assim a atividade coletiva organizada ou ação organizada. Isto é, adequada aos resultados desejados, factível com os recursos disponíveis, dividida de forma eficaz entre vários operadores e ordenada no tempo e espaço. Quando ela se reproduz regularmente, nasce o que se chama de organização.

\section{A coordenação da ação coletiva}

A realização do trabalho mediante a sua divisão pode ser um processo espontâneo; sobretudo, quando se trata de pequenos grupos ou de finalidades temporalmente limitadas. No entanto, a divisão pode também ser mais ou menos consciente, particularmente, quando há o incentivo da competição entre grupos pelos resultados da ação.

A divisão do trabalho entre vários operadores acarreta o estabelecimento de relações de trabalho entre os integrantes de uma cooperação. Tais relações podem ser momentâneas e instáveis, se eventuais. Tendem à estabilidade conforme aumenta a frequiência com que a cooperação se repete e produz resultados. Ao se repetirem, tais padrões de resultados, atividade e relações de trabalho provocam o surgimento de especializações profissionais no grupo e na sociedade. 
O grau de ordenação num sistema cooperativo pode variar muito: uma passeata em que todos seguem na mesma direção; a rudimentar divisão de funções de um time de futebol de várzea (goleiro, zagueiro e atacante) ou até a sofisticada divisão horizontal e vertical do trabalho numa grande empresa de alta tecnologia.

À medida que cresce o número de pessoas envolvidas numa ação organizada, mais refinada pode e precisa se tornar a divisão do trabalho. Com mais gente e maior subdivisão do trabalho, maior a necessidade de supervisores e, depois, de supervisores dos supervisores. Gera-se uma hierarquia de comando.

Basta pensar nas equipes de futebol de várzea para visualizar tais processos. A liderança emerge naturalmente. É o sujeito que arranja as partidas, que consegue o jogo de camisas, que sugere as táticas de jogo, que motiva o pessoal quando o jogo vai mal, que sugere melhor posicionamento durante um jogo, que recomenda ao colega que melhore seu passe de bola, que escala a substituição durante as partidas etc. Mesmo que haja muita negociação entre possíveis jogadores, rápido emergem um ou dois líderes nesse tipo de situação.

De início, os membros dessa hierarquia também realizam o trabalho direto. Entretanto, logo, alguns se especializam nos trabalhos relacionados à coordenação e às comunicações internas e externas. Basta pensar no capitão do time, que coordena dentro do campo, no técnico, que coordena as atividades de preparação, a escalação e define táticas, e no presidente do clube, que arranja recursos, lida com a federação de clubes etc.

Como mostrou Mintzberg (1980), os membros da hierarquia tendem a assumir as comunicações externas ao grupo e o acompanhamento do ambiente. Com isso, há uma diferenciação entre os indivíduos que se dedicam a executar o trabalho direto e os que participam das coordenações interna e externa dos diversos grupos. Assim, por essa via começa a se diferenciar um processo de tomada de decisões (administração) da execução das atividades coletivas (a ação organizada propriamente dita). Nasce o administrador profissional, executivo ou dirigente e a hierarquia administrativa ou divisão vertical do trabalho.

A cooperação é tanto mais complexa e dependente de coordenação também em função do tipo de relações que se estabelecem entre as diversas unidades que agrupam operadores. Como lembra Thompson (1967, p.54), a interdependência que a divisão do trabalho estabelece pode ser de três tipos: conjuntiva, seqüencial e recíproca:

- na interdependência conjuntiva, cada um precisa fazer a sua parte, mas o sucesso não depende de uma ordenação espaço-temporal precisa das ações individuais ou das diversas unidades que compõem a ação coletiva;

- na interdependência seqüencial, quem sucede não pode fazer sua parte sem que o antecessor cumpra a que lhe cabe;

- na interdependência recíproca de tarefas, as unidades são mutuamente dependentes.

É clara a necessidade de coordenação nos três casos e, também, que as interdependências seqüencial e recíproca tornam o sucesso mais dependente de melhor coordenação.

E se a rapidez é importante, quase sempre onde há competição, isso implica na necessidade de rápida integração das informações disponíveis em todo o campo relevante da atuação, de rápida tomada de decisão e de rápida disseminação das instruções de ação para os operadores. É só acompanhar o papel do capitão de um barco à vela numa regata para verificar como o simples desempenho - e mais ainda o alto desempenho ou o desempenho em condições desfavoráveis ou em competição - depende de coordenação eficaz e eficiente. Os partícipes de uma ação coletiva rapidamente se dão conta de que, se falhar a coordenação, não se chegará aos resultados pretendidos. Caso se chegue, serão insuficientes e insatisfatórios. É por isso que os capitães dos barcos que participam do America's Cup, por exemplo, são contratados entre os melhores; o que se afere por suas vitórias e participações destacadas em regatas e desafios importantes e reconhecidos. Quem coloca US \$150 milhões numa campanha não aceita coordenação de segunda classe. O princípio que rege a escolha de dirigentes e executivos é o mesmo: profissionais destacados e competentes, de desempenho reconhecido e confiável.

A coordenação do trabalho coletivo também toma a forma de padronização do trabalho e das competências necessárias à sua realização: daí advém a formação de profissionais especializados e a padronização tanto de processos de trabalho quanto dos produtos. Como frisa Mintzberg $(1979$, p.2), trata-se, nos três casos, de meios 
institucionalizados de coordenação do trabalho. Como conseqüência, os profissionais são obrigados a procurar posições onde haja demanda por suas competências especializadas e para as organizações se torna mais eficaz e eficiente desenhar postos de trabalho em torno de tais competências padronizadas, e assim dispor de um mercado de trabalho de especialistas padrão. Por vezes, terceiros interessados também querem tais profissionais e conseguem transformar suas preferências em exigência de compra ou obrigação legal. $O$ processo se completa quando a própria coordenação do trabalho se torna prática especializada de profissionais de gestão ou de executivos.

O fato é que a necessidade de coordenação aumenta, à medida que cresce o volume de trabalho coletivo organizado. Assim, gera-se uma realimentação positiva que sustenta e incrementa a atividade especializada de coordenação.

\section{Objetivos e resultados organizacionais}

Convém agora relembrar porque nasce a coordenação. Esta ajuda a suprir a ordem requerida para a divisão de trabalho na ação coletiva alcançar os resultados desejados. Não precisa ser consciente; basta contemplar um grupo de leoas caçando para ver coordenação sem consciência explícita. Barnard (1942, p.73), entretanto, ao tratar de organizações, assim as define: "Um sistema conscientemente coordenado de atividades ou forças de uma ou mais pessoas" (tradução do autor). ${ }^{8}$

O autor (Idem, 1942, p.75, nota 7), trata essa definição como uma abstração. Análoga à noção de alavanca perfeita de Arquimedes, de gás perfeito da teoria cinética dos gases, de campo eletromagnético na física da eletricidade ou de espécie na biologia. Uma abstração serve para deixar explícitas as propriedades relevantes do objeto, isoladas para o estudo e teorização sobre os fenômenos dos quais o objeto participa. Sua validade - ou a extensão de sua aplicabilidade aos fenômenos de interesse, é claro -, dependerá de se submeter ao teste empírico a teoria resultante.

Barnard recorre à palavra "conscientemente", o que exige esclarecimento. Barnard (1942, p.82) sugere que Uma organização começa a existir quando: "1) existem pessoas capazes de se comunicar umas com as outras, que 2) se dispõem a contribuir com suas ações para 3) realizar um propósito comum."

Ao conjugar "sistema de atividades conscientemente coordenado" e "propósitos comuns", Barnard enfatiza a relação entre meios e fins. Segue Weber e traz a idéia de racionalidade para o âmago da noção de organização.

Será que se pode falar de finalidades organizacionais ou propósitos comuns?

Mintzberg (1983, cap.2) dedica um capítulo de seu livro a uma revisão da literatura sobre o propósito das organizações. O autor (Idem, 1983, p.246-247) conclui que as organizações têm, sim, propósitos que podem ser vistos em, pelo menos, quatro casos claros:

- quando há uma ideologia dominante, em relação a qual os membros de uma organização partilham um conjunto de crenças;

- quando um ator dominante impõe seus objetivos à organização, obtendo a cooperação dos demais participantes;

- quando um grupo de indivíduos tem objetivos comuns e criam (ou se juntam a uma) organização para facilitar o alcance desses objetivos; ou

- quando a simples existência da organização beneficia seus membros.

Nesse último caso, surgem os objetivos chamados de sistêmicos pelo autor:

- a sobrevivência da organização;

- certo nível de eficiência para assegurar essa sobrevivência;

- independência em relação a terceiros; e (mais importante dentre estes) 
- o crescimento.

Como é óbvio, nada impede que objetivos sistêmicos estejam presentes também nas outras situações.

Mintzberg deixa claro, também, que os objetivos da organização não precisam ser comuns aos de seus membros e que freqüentemente são objeto de disputa, somente ficando estabelecidos quando uma coalizão dominante consegue determiná-los. Mintzberg lembra ainda que a disputa sobre os objetivos pode levar a organização à paralisação e à atuação inconsistente e ineficaz. Isso caracterizaria uma situação instável, que tende a ser superada pela ascensão de uma coalizão dominante ou pela dissolução da organização.

E quanto aos demais membros, fora da coalizão dominante? Resta-lhes submeterem-se, saírem ou serem excluídos da organização ou, mesmo, receberem incentivos para ficar e contribuir com seu trabalho. Para os dissidentes, há também a opção de submeterem-se, temporariamente, dissimulando a divergência, no aguardo de novas oportunidades para alterarem os objetivos organizacionais de que discordam. É uma saída muito mais comum do que se imagina, quando o indivíduo ou grupo tem muito a perder com a saída e muito a ganhar com a mudança dos objetivos da organização.

Fica claro assim que os objetivos organizacionais apenas formalizam, na esfera intersubjetiva, os resultados da ação coletiva que a coalizão dominante elegeu como alvo. No entanto, os dirigentes são cobrados pela correspondência entre resultados obtidos e esperados.

A literatura capta essa sutileza quando faz a distinção entre objetivos explícitos e operacionais (PERROW, 1961). O que se distingue aqui são os resultados efetivamente avaliados na ação e os objetivos formalizados nos estatutos e cartas de intenções da organização. Cuida-se assim da distância entre "intenção e gesto", realçando os objetivos revelados pela ação e pelos sistemas de avaliação aplicados.

O ponto central aqui está em que tais objetivos não são apenas idéias arbitrárias na mente dos membros da organização. Eles são a explicitação dos resultados esperados pela coalizão dominante da organização, suas expectativas. Manifestam-se em bens e serviços que a organização precisa produzir e entregar. Têm, portanto, existência real e independente da vontade do administrador e de seus subordinados; ${ }^{10}$ tão real que sistemas e metodologias como administração por objetivos e sistemas de indicadores foram criados para aferir o alcance dos objetivos pela organização e seus membros. ${ }^{11}$

\section{Resultados e reprodução da organização}

A partir de Barnard, a noção de organização foi ficando mais relacionada à noção de sistema. A ênfase tem sido a de que, por tratar-se de processos e relações, pesquisar a organização supõe conhecer as inter-relações internas e externas que constituem a sua própria realidade.

No entanto, há outro conjunto de temas relacionados à noção de sistema tão importantes quanto este para o completo entendimento da idéia de organização. Em sua concepção formal, um sistema é constituído de entradas, processos e de saídas, as quais, por sua vez, são realimentadas nas entradas.

A verificação de variações na saída do sistema num ciclo de operação pode garantir informações que possibilitem corrigir as entradas nos ciclos subsequientes, trazendo a saída para mais perto do esperado. Trata-se aqui do controle do desempenho contra padrões que podem ser deliberados ou impostos pelas circunstâncias, no sentido de suficientes para a continuidade da operação do sistema.

No caso do tratamento de organizações como sistemas, essa acepção do sentido de retroalimentação vem sendo bastante utilizada. Afinal, é a que mais se coaduna com a idéia de organização formal e racional que dirige e controla a ação coletiva contra planos deliberados.

Contudo, outra noção subjacente, típica das organizações e não dos sistemas em geral, talvez, seja até mais importante na caracterização das organizações como sistemas: é o fato de que as entradas das organizações são conseqüências das suas saídas! Na verdade, no ambiente de divisão social de trabalho entre organizações e indivíduos, as organizações trocam as saídas de um ciclo de atividades pelas entradas necessárias ao ciclo 
seguinte. Nas organizações, a retroalimentação não se limita ao retorno de informações para o controle refinado do próximo ciclo. Muito mais que isso, os próprios recursos necessários ao próximo ciclo de operação dependem dos resultados obtidos no ciclo anterior. Se a organização não rende o suficiente para viabilizar o próximo ciclo de operação, e a insuficiência é sistemática, ela fenece! Como a organização acumula reservas e a insuficiência de desempenho pode ser pequena, tal processo não precisa ser instantâneo - no ciclo imediato. No entanto, ao se tornar sistemática, a insuficiência de desempenho inviabiliza a organização.

Convém lembrar aqui que os recursos para o primeiro ciclo não resultam de ciclo anterior da mesma atividade. Trata-se do investimento inicial que provém de outras fontes. Contudo, uma vez iniciado o processo, é preciso repor tais recursos ou receber novas contribuições de terceiros, o que demanda capacidade de obtenção de tais doações.

Ao contrário do que possa parecer, essa situação vale para todas as organizações. Uma igreja só tem recursos para operar se receber doações em valor suficiente dos fiéis. Isso só ocorre se um número suficiente deles satisfizer suas necessidades espirituais e de convivência religiosa. Uma organização criminosa só consegue operar se obtiver os recursos necessários; no caso, para recrutar bandidos em número suficiente e mantê-los sob controle.

Da mesma forma, uma organização governamental precisará convencer os órgãos orçamentários a lhe fornecerem os recursos; o que depende do exercício das atividades previstas para ela e da habilidade de convencer o Tesouro e quem influencia suas decisões. O próprio governo, como um todo, quando falhar com o público, pode ser surpreendido, em casos extremos, por uma rebelião ou, na situação mais comum, pela sonegação ou pela informalidade.

A organização precisa ter sucesso em suas atividades geradoras de recursos. Do contrário, morre e não realizará mais nada! Por isso, a atividade principal da organização está de perto associada à geração de recursos suficientes para seu funcionamento. Quando isso não ocorre, algo está oculto. Vale a pena checar a correlação entre intenção e gesto. Será que a organização realmente vive do que alega fazer? Provavelmente, não; como é o caso da lavagem de dinheiro, por exemplo!

A concepção sistêmica, quando bem aplicada às organizações, ajuda a formalizar o fato de que o processo, o funcionamento das organizações, depende diretamente do sucesso nas suas atividades! Isso porque os resultados viabilizam os recursos necessários aos próximos ciclos de funcionamento, o que empresta enorme objetividade à atividade organizada.

Além disso, deve ser ressaltado que o desempenho não depende apenas de diligência, competência e dedicação. Fatores contingentes do ambiente também afetam a natureza e a magnitude dos resultados obtidos pela atividade organizada. Isto é, a organização não pode ser tratada como um sistema fechado, pois não teria como continuar a existir, já que é no seu ambiente que os resultados são obtidos. Qualquer conceito de organização deve render homenagem à idéia de abertura ao ambiente. Abertura que pode ser controlada, ainda que parcial e não totalmente; levando-se em conta, é óbvio, que a incerteza tem grande impacto sobre a forma de administrar e organizar (THOMPSON, 1967).

\section{Campos ou domínios da ação coletiva organizada}

Como diz Thompson (1967, p.6), as organizações sofrem limitações nas suas ações pela ação de outras unidades sociais, ou "os melhores planos dos dirigentes têm conseqüências imprevistas e são condicionados e perturbados por outras unidades sociais - organizações complexas ou públicos - de quem a organização depende" (tradução do autor) ${ }^{12}$. A literatura reflete com clareza a diferença entre "intenção e gesto" quando discute os campos ou domínios da ação coletiva (THOMPSON, 1967, cap.3).

A organização precisa de meios para reproduzir a ação coletiva organizada, incluindo as próprias pessoas que realizam tais ações. Os meios para isso, são obtidos da sociedade em retribuição pelos bens e serviços fornecidos. Nessa troca, a organização tem concorrentes, o que a força a melhorar seu desempenho quanto aos bens e serviços que produz e entrega. É o campo ou domínio da ação organizada que lhe impõe severas 
restrições sobre o que pode produzir e como. Ela não é livre para definir seus objetivos operacionais a seu belprazer, sob pena de não sobreviver.

Essa idéia de campos ou domínios da ação organizada nasceu, justamente, da necessidade de contornar o elemento subjetivo da idéia de objetivo organizacional. A idéia é simples: separar o que é objetivo nas intenções dos membros da organização daquilo que é subjetivo. São objetivos os resultados que são cobrados por terceiros externos à organização. Na moderna terminologia da estratégia empresarial, o grande herdeiro dessa idéia é a caracterização do ambiente competitivo de Porter (1983). Acionistas, empregados, profissionais, fornecedores, clientes, concorrentes, terceiros interessados, governos etc. exigem resultados das organizações, na forma de paga ou de outras recompensas, sob o risco de subtrair sua contribuição.

Resultados, na forma de pagamentos, lucros, bens, serviços e externalidades são estreitamente monitorados e cobrados por múltiplos interlocutores internos e externos da organização. Assim, os bens e serviços produzidos e entregues pela organização são fundamentais para que ela obtenha os recursos necessários a sua reprodução. Ao mesmo tempo, todas as exigências técnicas sobre o trabalho da organização decorrem do que ela tem de entregar e dos meios que mobiliza para produzi-lo. Trata-se das entradas e das saídas do sistema de ação coletiva, cujo processo se repete ou se reproduz. Nasce assim o conceito de ambiente de tarefa. $\mathrm{O}$ que precisa ser feito e como, na ação coletiva.

Eis que a idéia romântica de objetivos como mera intenção subjetiva logo se dissolve. É claro que objetivos são intenções na mente de indivíduos específicos. Entretanto, também é claro que não podem ser fruto do arbítrio individual. Eles são instrumentais na produção dos efeitos materiais cobrados por terceiros. Essas cobranças dominam a ação coletiva organizada, porque é enorme o poder conjunto de investidores, clientes, poder público, fornecedores chave, empregados, dentre outros, o que estabelece rigorosas restrições sobre quais objetivos devem ser por ela alcançados. Estabelecem inclusive os padrões de eficiência e eficácia visados; como evidencia a simples lembrança da intensa concorrência por recursos e clientela.

Outras restrições do campo de ação determinam como os resultados podem ser alcançados. Por exemplo, danos a terceiros dão ensejo a pedidos de reparações, que, bem-sucedidos diminuem a parcela de resultados efetivamente disponíveis para o suporte da organização.

Essencialmente, a idéia de campos ou domínios da ação organizada mostra que apesar de objetivos serem intenções subjetivas, eles também precisam manter estreita conexão com o mundo social a sua volta, não podendo ser arbitrários. O mesmo vale para as restrições físicas sobre os objetivos, que não podem ser ignoradas, sob pena de não se alcançar os resultados esperados e frustrar seus destinatários. Objetivos organizacionais não são intenções individuais arbitrárias. Ao contrário, são intenções intersubjetivamente partilhadas, disputadas por partes interessadas e fortemente ancoradas numa realidade social e física que cerca a organização e não deixa margem para devaneios solipsistas.

\section{A autoridade real da hierarqula e a decisão de participar}

As ações organizadas, muitas vezes, nascem voluntárias. Adere a elas quem aceita participar. É assim, por exemplo, com igrejas, clubes de serviços, partidos políticos e associações civis, em geral. Mesmo nessas, contudo, logo é preciso um quadro dirigente (WEBER, 2004, p.30) que se dedica às funções mais demandantes da entidade e que assegura a constância de objetivos e o cumprimento das regras coletivamente estabelecidas na ação organizada. Não se propõe aqui confundir participação voluntária com democracia interna e externa. Apenas frisar que os membros das organizações voluntárias acabam se submetendo a imposições sobre o conteúdo e a forma do trabalho a ser realizado coletivamente, gerando uma hierarquia de comando que zela pela ortodoxia. Quando instalada, essa hierarquia inclusive, pune e até exclui os recalcitrantes.

Somente associações voluntárias não dão conta de todo o trabalho que precisa ser realizado. Nas sociedades mais primitivas isso levou ao trabalho forçado e à escravidão; eficazes e sustentáveis apenas sob condições técnicas primitivas e de baixíssima produtividade. 
Nas complexas e modernas sociedades industriais, prevalece o trabalho pago. A forma principal de mobilização de pessoas para participar da divisão de trabalho interna às organizações é o contrato voluntário de trabalho. Barnard (1942) e Simon (1997) frisam que o indivíduo é livre para contratar os seus serviços a quem quiser pagar por eles. Ressaltam que há um limite muito claro para o exercício do poder e da autoridade na organização, que é o assentimento do contratado.

Para alguns poucos indivíduos altamente qualificados ou detentores de competências muito procuradas há realmente uma alta dose de voluntariedade na decisão de participar. Frequientemente, porém, tais profissionais exercem atividade autônoma prestando serviços mediante paga caso a caso. Nem se interessam, muitas vezes, por um emprego. Teriam menos liberdade para fechar negócios melhores e ganhariam menos.

Como é fácil ver, essa formulação esquece que para sobreviver o indivíduo precisa de recursos que só consegue trabalhando mediante contrato. Esquece também que a padronização profissional vincula o indivíduo não só a uma classe de postos de trabalho, como também o põe em concorrência com outros indivíduos na conquista de tais postos. Uma alternativa é o trabalho avulso que é de menor remuneração e incerto ou altamente exigente e para poucos. Outra opção é tornar-se líder de uma empresa, para o que poucos têm as habilidades e os recursos requeridos para sobreviver e prosperar na dura competição do mercado empresarial. Como frisou Marx (1980), a maioria dos membros da sociedade moderna, não proprietários de meios de produção, para sobreviver, têm de alugar sua força de trabalho num mercado com um exército de reserva, auto-regulado pelos ciclos de expansão e crise dos negócios. Em termos modernos, aliás, o excesso de oferta de trabalhadores é explícita e deliberadamente mantido pela política antiinflacionária dos bancos centrais.

Assim, é de fato voluntária a decisão de participar de uma particular organização, nas raras ocasiões em que há abundante oferta de emprego, logo antes das crises. No entanto, poucos têm a opção de ficar fora de qualquer organização. Desses poucos, a maior parte trabalha avulso para essas organizações ou para as famílias que delas tiram seu sustento. Em geral, tais trabalhadores vivem e trabalham em condições precárias em relação aos regularmente empregados.

Um ponto omitido por Simon e Barnard é a escolha do empregador. Ele decide quem contratar e quando demitir. Leva em conta habilidades aferíveis ou comprováveis, além do histórico de trabalho assalariado do indivíduo. Onde todos os possíveis empregados são recalcitrantes, isso tem valor menor. Entretanto, onde a mão-de-obra já está treinada na disciplina do trabalho assalariado e há muita concorrência entre candidatos, essa possibilidade de seleção muito contribui para o assentimento do empregado.

Por isso, o poder de empregar e demitir faz muita diferença no poder interno às organizações. Quem controla os fluxos de recursos, proprietários e dirigentes, têm meios adicionais de exercer a coordenação do trabalho numa sociedade em que todos precisam de emprego para viver.

Por outro lado, a divisão do trabalho torna os participantes dependentes da organização. Se o conjunto não alcança os resultados em grau suficiente, todos sofrem as consequiências - menores salários e desemprego. Daí que o sucesso na coordenação interessa muito a todos os participantes da ação coletiva, estabelecendo novo mecanismo de reforço para a dedicação do empregado e para a profissionalização da atividade de coordenação ou gestão. ${ }^{13}$

Por fim, nesse ambiente, o empregado - seja mão-de-obra, seja dirigente - nem sempre opta por sair quando discorda. Muitas vezes, decide esperar uma oportunidade para mudar a situação a seu favor. Uma possibilidade maior, é claro, quanto mais poder o indivíduo desfrutar na organização. Como brinca Mintzberg (1983, p.210216) é a "revolta dos jovens turcos" (tradução do autor) ${ }^{14}$.

No fundo, esclarece Thompson (1967, p.26), poder sobre as organizações é o controle sobre os meios de que dependem. Isso vale para as relações entre organizações, assim como para relações entre elas e os indivíduos. É tamanho esse poder, que mecanismos institucionais mais abrangentes na sociedade buscam limitá-lo.

O que resulta da discussão sobre coordenação, hierarquia e decisão de participar é que a autoridade da hierarquia na organização é real. É exercida por muitos meios: uns são coercivos; outros, persuasivos e, alguns, negociais. Embora limitada na sua abrangência e profundidade, a autoridade não é mera questão de concessão 
do empregado, como sugeriram Barnard (1942) e Simon (1997). Não está, como pensam alguns, apenas na cabeça das pessoas, mas nas reais relações de poder. Faz parte intrínseca da realidade da ação organizada que só alcança os resultados necessários à sua reprodução mediante cooperação, coordenação, recursos, conhecimentos e habilidades.

\section{Poder e resultados na ação organizada}

Basta refletir minimamente sobre a miríade de atividades de uma sociedade industrial moderna para perceber que a divisão do trabalho é absolutamente necessária e bem-vinda, mesmo, com os problemas que pode acarretar. Sem ela, a medicina moderna seria impossível, como também seria impossível a democracia moderna ou a ciência atual. Igualmente impossíveis seriam o turismo de massas e as comunicações instantâneas a longas distâncias, só para mencionar casos óbvios.

O fato elementar a destacar é que a divisão e coordenação do trabalho produzem resultados qualitativos e quantitativos impossíveis na sua ausência. Como frisa Giddens (1993, p.116-120), poder tem relação com a capacidade de mobilizar os meios para realizar algo. No sentido sociorrelacional, poder aparece quando tais meios envolvem a ação de terceiros. Quer dizer, quando é preciso por outrem a agir; ou seja, é preciso organização.

Assim, um elemento central do poder é a capacidade de obter resultados. Isso abre caminho para entender o poder nas ações coletivas organizadas. O poder é um fenômeno multifacetado, mas, sem dúvida, uma de suas facetas é a consecução de resultados. Um líder rápido se constitui quando seus possíveis seguidores se convencem que segui-lo produz os resultados desejados: presas na caçada, vitória na batalha, riquezas nos negócios, elevação espiritual no serviço religioso, conhecimento e habilidades no ensino etc.

Quem se mostra capaz de exercer a coordenação eficaz ganha poder sobre os participantes da ação organizada, enquanto o grupo tende a atender aos seus comandos. Da própria coordenação necessária ao trabalho coletivo começa a nascer um sistema de poder hierárquico na organização. Portanto, não se pode entender a realidade das organizações sem entender que elas exigem um sistema de poder interno e externo.

Embora fatores aleatórios contribuam para os resultados, fatores não-aleatórios são muito importantes; particularmente, para resultados consistentes no tempo.

Um fator vital na coordenação é o conhecimento de como melhor dividir o trabalho a ser realizado ou sobre onde e como aplicar os esforços antes, durante e depois da realização do trabalho para alcançar melhores resultados. Afinal, uma equipe de futebol que põe o próprio ataque atrapalhando a defesa não ganha muitas partidas. Aliás, no futebol altamente competitivo de hoje, se o ataque não colaborar com a defesa quando o time perde a posse da bola, ou vice versa, logo, a equipe perde posições no campeonato. Da mesma forma, é vital o conhecimento das tecnologias aplicáveis ao trabalho e sobre como utilizá-las eficaz e eficientemente.

Aquele que sabe o quê e como fazer, ou que conta com o apoio de quem saiba, rápido assume a liderança e a direção do trabalho.

Outro fator-chave é controlar os recursos necessários. Se alguém controla os recursos adequados para a realização de uma ação coletiva, esse alguém tem lugar de destaque na equipe. Se seus recursos forem vitais ao sucesso, seu titular terá condições de reivindicar recompensa maior na divisão dos resultados e, até, posição de mando na ação coletiva. Do contrário, omitirá a cessão dos recursos que controla. Assim, regimes de propriedade (MARX, 1980) são aspectos centrais de como a organização depende de macroestruturas sociais para estabelecer as hierarquias de mando. Da mesma forma, quando a tecnologia passou a incluir maquinaria sofisticada conjugada à mão-de-obra de baixa qualificação, um elemento adicional de controle sobre o trabalho apareceu. A mão-de-obra fácil de substituir ficou obrigada a se acomodar às ofertas e exigências do empregador.

Mesmo com histórico favorável de resultados alcançados, um líder e coordenador precisará persuadir, se não todos, pelo menos alguns a realizarem as tarefas que lhes serão atribuídas na divisão do trabalho. Um bom dirigente precisa persuadir seus seguidores e subordinados do valor dos fins perseguidos e da adequação dos 
meios empregados; particularmente, dos esforços e eventuais sacrifícios que se solicita de cada um. Não é tarefa fácil, considerando-se a enorme variedade de motivações, inteligência, conhecimento e habilidades dos seres humanos, em geral, e dos que são mobilizáveis para uma tarefa, em especial. Essa idéia do poder ideológico é antiga. Marx a concebe em termos de justificativas gerais para o direito de mandar. Weber a trata como parte do carisma do líder. Gullick $(1937$, p.6) a menciona como o domínio de uma idéia que define o propósito da organização. Mintzberg (1983), por sua vez, a inclui no seu sistema de poder quase como um ator da coalizão dominante, embora, para ele, é claro, trata-se apenas de convicções compartilhadas e sistematicamente reforçadas pela situação da organização e por seus líderes.

Por fim, o instrumento das recompensas e punições é de especial eficácia. Em conjunção com recursos necessários, conhecimento, coordenação eficaz e persuasão, as recompensas e punições reforçam a capacidade de coordenação do dirigente. Recompensas, só com recursos. A punição mais dura pode ser a retenção da recompensa por esforço insuficiente. Pode ser também a exclusão do grupo e de todas as oportunidades futuras de partilhar seus resultados e recompensas. Assim, uma grande recompensa é a própria chance de integrar o grupo em caráter permanente.

O que a argumentação anterior mostra à socapa é que não há divisão de trabalho eficaz na ação coletiva sem uma hierarquia de poder. Isso fica ainda mais evidente quando se cogita sobre o que seria preciso para garantir a cooperação sem qualquer elemento de poder. Os investimentos necessários precisariam ser fornecidos sem qualquer condição, de modo eficaz. O conhecimento precisaria ser gerado e oferecido sem qualquer contrapartida. Não poderia haver recalcitrantes, nem situações especiais que exigissem sacrifícios especiais de alguém. Se a liderança e coordenação de alguém fossem necessárias, o indivíduo de maior capacitação seria espontaneamente reconhecido e seguido pelos membros voluntários do esforço. É claro que a divisão eficaz do trabalho exigiria total concordância sobre quais resultados alcançar, quais meios e qual divisão de esforços entre os participantes, bem como quanto à divisão das recompensas, custos e esforços. Sem dúvida, tudo isso poderia eventualmente acontecer. Mas de modo sistemático, eficaz e eficiente, para qualquer organização em todas as suas tarefas ao longo de décadas? Certamente, não.

Assim como não há organização sem divisão e ordenação espaço-temporal do trabalho, tampouco existe ação coletiva organizada sem hierarquia de comando e, portanto, sem exercício do poder, no sentido sociorrelacional. Resultados legitimam o poder dos dirigentes que a ele recorrem para viabilizar os resultados esperados da ação coletiva, criando um círculo de ferro inescapável. Resultados legitimam o poder que viabiliza os resultados.

\section{Uma tentativa de concepção crítica e objetiva}

Um conceito crítico e objetivo de organização precisa incluir as seguintes idéias:

- organizações não são coisas, nem grupos, mas sistemas sociais abertos de processos e inter-relações envolvendo pessoas que produzem resultados;

- as atividades que integram os processos se encontram divididas e ordenadas espacial e temporalmente. Sua execução exige coordenação e recursos, dentre esses conhecimentos e habilidades;

- os recursos para um ciclo de operação provêm do resultado de ciclos anteriores;

- os resultados decorrem da inserção da organização num campo ou domínio social;

- o domínio social restringe os resultados dela esperados e seus objetivos operacionais, assim como impõe inúmeras exigências e regras para sua operação;

- e tudo isso acarreta uma hierarquia de comando e um sistema de poder para garantir a execução espacial e temporalmente ordenada das atividades da organização.

Numa definição de organização com os elementos anteriormente citados não há traço de subjetividade. Ela é objetiva. Independe do que se passa na cabeça dos participantes envolvidos. Só entra na definição o que eles fazem, como eles fazem e os resultados obtidos. Todos são aspectos observáveis da realidade empírica. Em 
particular, tal definição evita se enredar no pântano da idéia de racionalidade. Sequer se utiliza a noção de causa, apenas, as de sequiência, inter-relação e correlação. Tampouco se utiliza a noção de finalidade ou de objetivos comuns. O que se observa são processos com resultados, bens e serviços, sistematicamente correlacionados.

Os resultados definem o propósito da atividade coletiva em termos não intencionais - por exemplo, fazer automóveis ou prestar serviços religiosos específicos. Sem resultados, a organização não se mantém, já que os recursos para sustentar suas atividades dependem do sucesso no alcance de resultados suficientes nessas atividades. Além disso, na maior parte dos casos relevantes, há muita concorrência e disputa pelos mesmos recursos.

A organização não existe num vácuo. Ela se encontra cercada de outras organizações, instituições e indivíduos e de todo um sistema social que cobra resultados para fornecer os recursos necessários e estabelece regras de operação e restrições para a ação de seus membros. Há todo um aparato institucional regulando contratos para gerar regras aplicáveis e coagir os recalcitrantes a segui-las. Existe a obrigação de partilhar os resultados, através dos impostos. Salários são regulados, assim como as condições de trabalho. Produtos e serviços oferecidos obedecem a padrões mínimos. Da mesma forma, o sucesso na busca dos resultados depende de que se atenda às demandas de colaboradores, fornecedores, clientes e autoridades. Nada disso é subjetivo!

Uma concepção como essa nos permite tratar da organização numa perspectiva objetiva no plano ontológico. Basta aceitar que processos e relações façam parte da realidade tanto quanto coisas. Convém frisar que não aceitar a realidade de processos e relações implica não aceitar um atropelamento como real, e que uma vítima potencial poderia escapar do caminhão só com uma redefinição mental da situação. É preciso descartar a idéia da organização como uma coisa que possa ser agarrada, o que não quer dizer que só exista na cabeça das pessoas. Ao contrário, ela existe no padrão das relações entre pessoas que cooperam. Com o passar do tempo, todas as pessoas podem ser substituídas e, ainda assim, a organização continuaria a existir, como uma onda na água. É o caso, aliás, da própria pessoa, composta de células que morrem e são substituídas sem que ela deixe de existir.

No plano epistemológico, a concepção de organização aqui exposta abre a possibilidade de teorização e modelagem objetiva de processos e relações com base em fatos e eventos experimentados e experimentais. Permite a pesquisa objetiva sobre as organizações e sua administração. É também uma concepção crítica porque não presume a racionalidade e a eficiência como elementos constituintes da própria idéia de organização. Há organizações irracionais e ineficientes que a crítica ajuda a melhorar e até substituir!

Não é o propósito deste artigo oferecer uma definição formal de organização. O propósito, lembre-se, foi o de oferecer critérios para a crítica objetiva. Mesmo assim, não é ocioso um exercício que permita enxergar o que pode resultar dos critérios anteriormente tratados. Seguindo Barnard, a noção de organização bem poderia ser formalizada como um sistema cooperativo de producão de bens e servicos com um padrão durável ${ }^{15}$ de divisão de trabalho e relacões de poder. 


\section{Referênclas}

BARNARD, C. I. The functions of the Executive. Third printing. Cambridge, MA: Harvard University Press. 1942.

BERTERO, C. O. Teoria das organizações e sociedades subdesenvolvidas. Revista de Administração de Empresas, São Paulo, v.32, n.3, p.14-28, jul./ago. 1992.

DA COSTA, N. C. A. Ensaio sobre os fundamentos da lógica. 2.ed. São Paulo: Editora Hucitec, 1994.

FAYOL. H. Administração industrial e geral. 8.ed. em português. São Paulo: Editora Atlas S.A., 1970.

GIDDENS, A. New rules of the sociological method. $2^{\text {nd }}$ ed. Stanford, CA: Stanford University Press, 1993.

GOULBNER, A. W. Organizational Analysis. In: MERTON, R. K., BROOM, L. e COTTRELL, JR., L. S. Sociology Today - Problems and Prospects. American Sociological Society. $4^{\text {th }}$ printing. Basic Books, Inc., Publishers, New York. 1961 (Copyright 1959).

GULLICK, L. Notes on the theory of organization. In: .; URWICK, L. Papers on the science of administration. New York: Institute of Public Administration, Columbia University, 1937.

MARCH, R.; SIMON, H. A. Organizations. [S.I.: s.n.], 1958.

MARX, K. O capital - crítica da economia política. 5.ed. Tradução: Reginaldo Sant'Anna. Rio de Janeiro, RJ: Editora Civilização Brasileira, 1980.

MINTZBERG, H. The nature of managerial work. Englewood Cliffs: Prentice Hall, 1980 (Original 1973). . The structuring of organizations. Englewood Cliffs: Prentice Hall, 1979. Power in and around organizations. Englewood Cliffs: Prentice Hall, 1983.

PERROW, C. The analysis of goals in complex organizations. American Sociological Review, v.26, n.6, p. 854-856, 1961. PORTER, M. E. The Competitive Strategy. The Free Press. New York. 1980.

NASCIMENTO, P. T. S. A interpretação objetiva em administração. In: ENCONTRO DA ANPAD - Enanpad, 31., 2007. Anais... Rio de Janeiro: Anpad, 2007.

POPPER, K. R. Conjectures and refutations - the growth of scientific knowledge. Routledge. London e New York. 2002 (1963).

ROSEMBERG, A. Philosophy of science - a contemporary introduction. $2^{\text {nd }}$ ed. New York: Routledge, 2005.

RUSSELL, B. A History of Western Philosophy. Simon \& Schuster. New York. 1945.

RUTGERS, M. R. Be rational. But what does it mean? A history of the idea of rationality and its relation to management thought. Journal of Management History, Bradford, v.5, n.1, p.17, 1999.

SIMON, H. A. Administrative behaviour. [S.I.:S.n.], 1997.

SMITH, A. Investigação sobre a natureza e as causas da riqueza das nações. 2.ed. São Paulo: Abril Cultural, 1979. (Coleção Os Pensadores).

THOMPSON, J. D. Organizations in action - social science bases of administrative theory. New Brunswick (USA): Transaction Publishers, 2006 (original 1967).

WEBER, M. Economia e sociedade, [S.I.: s.n.], 2004.

\footnotetext{
${ }^{1}$ Organizations are assemblages of interacting human beings and they are the largest assemblages in our society that have anything resembling a central coordinative system. [...] the high specificity of structure and coordination within organizations - as contrasted with the diffuse and variable relations among organizations and unorganized individuals - marks off the individual organization as a sociological unit comparable in significance to the individual organism in biology.

2 it is easier, and probably more useful, to give examples of formal organizations than to define them [...] we need not trouble ourselves about the precise boundaries to be drawn around an organization or the exact distinction between "organization" and "non organization".

${ }^{3}$ Aqui, os termos "prolixo" e "desajeitado" se referem apenas à terminologia. Não indicam que a proposição seja ruim ou falsa. Menos ainda se aplicam ao autor, que ao escrever lutava com a dupla dificuldade de criar novos conceitos e inventar nova terminologia.
} 
${ }^{4}$ Clareza e rigor são exigências da construção social do conhecimento, para evitar confusões e facilitar o entendimento e a contribuição dos outros. Clareza é, evidentemente, um valor epistêmico que se justifica, em primeiro lugar, num contexto social de produção do conhecimento. Só depois é que se torna um valor na reflexão individual. O mesmo vale para o rigor. O rigor adquire sentido no processo de crítica, e só depois no de autocrítica. O rigor é uma exigência do diálogo construtivo. Se ao usar o mesmo termo duas pessoas engajadas num diálogo trabalharem com noções que mudam de sentido em aspectos relevantes a cada uso, o entendimento mútuo e até individual se complica e a confusão se instala, impedindo a construção social do conhecimento.

${ }^{5}$ Mesmo assim, um grupo adequado de pessoas, qualquer que seja, é necessário para manter a organização. Sem pessoas em número suficiente e com as características necessárias, a organização não pode subsistir.

${ }^{6}$ Se alguém se socorrer de um dicionário para achar o sentido da palavra organização, vai se deparar com definições do tipo (Houaiss): "entidade que serve à realização de ações de interesse social, político, administrativo etc.; instituição, órgão, organismo, sociedade; grupo de pessoas que se unem para um objetivo, interesse ou trabalho comum; associação; conjunto de normas e funções que têm por objetivo propiciar a administração de uma empresa, negócio etc.; ordenação das partes de um todo; arrumação".

${ }^{7}$ Because men differ in nature, capacity and skill, and gain greatly in dexterity by specialization; Because the same man cannot be at two places at the same time; Because the same man cannot do two things at the same time; Because the range of knowledge and skill is so great that a man cannot within his life-span know more than a small fraction of it.

8 "a system of consciously coordinated activities or forces of one or more persons".

9 "an organization comes into being when (1) there are persons able to communicate with each other, (2) who are willing to contribute action, (3) to accomplish a common purpose".

10 Isso não significa que os administradores não possam influenciar os objetivos da organização. Apenas, não podem violá-los impunemente.

${ }^{11}$ Claro que tais sistemas também mostram problemas de medição. Por exemplo, quando se trata de diferir resultados entre períodos ou, então, quando um aparente fracasso num determinado instante revela-se grande sucesso com o passar do tempo. Aparece assim o problema do tempo na medição de resultados. Outra dificuldade é a atribuição da contribuição de uma determinada atividade ou investimento para o resultado final. Entretanto, tais problemas reais e práticos não alteram a possibilidade de interpretação objetiva, embora, muitas vezes a compliquem.

12 "the best-laid plans of managers have unintended consequences and are conditioned or upset by other social units - complex organizations or publics - on whom the organization is dependent".

${ }^{13} \mathrm{O}$ que não impede o aproveitador de querer tirar vantagem, sem nada ou pouco contribuir. No entanto, isso o torna antipático, não só para a organização, como até para os colegas empregados, que deverão suprir os seus serviços precários com esforço adicional.

14 "young Turks revolt".

${ }^{15}$ Durável aqui quer dizer um período bem maior do que o necessário a um ciclo de produção dos bens e serviços e sem prazo definido para acabar. A organização pereniza a ação coletiva. 